\title{
Transformation of an Agulhas eddy near the continental slope
}

\author{
S. Baker-Yeboah ${ }^{1}$, G. R. Flierl ${ }^{1}$, G. G. Sutyrin ${ }^{2}$, and Y. Zhang ${ }^{1}$ \\ ${ }^{1}$ Department of Earth, Atmospheric, and Planetary Sciences, Massachusetts Institute of Technology, \\ Cambridge, MA 02139, USA \\ ${ }^{2}$ Graduate School of Oceanography, University of Rhode Island, Narragansett, Rhode Island 02882, USA
}

Received: 8 July 2009 - Published in Ocean Sci. Discuss.: 19 August 2009

Revised: 15 January 2010 - Accepted: 20 January 2010 - Published: 2 February 2010

\begin{abstract}
The transformation of Agulhas eddies near the continental slope of southern Africa and their subsequent self-propagation are analyzed in both observational data and numerical simulations. Self-propagation results from a net dipole moment of a generalized heton structure consisting of a surface-intensified anticyclonic eddy and deep cyclonic pattern. Such Agulhas vortical structures can form near the retroflection region and further north along the western coast of southern Africa. We analyze nonlinear topographic wave generation, vortex deformations, and filament production as an important part in water mass exchange. Self-propagating structures provide a conduit for exchange between the deep ocean and shelf regions in the Benguela upwelling system.
\end{abstract}

\section{Introduction}

Although the wind stress curl is the single most important factor in shaping a multi-cell upwelling system along the coast of South Africa, Agulhas rings and remnant Agulhas rings can drive water offslope and offshelf in the Benguela upwelling system between Cape Town and Walvis Bay. Agulhas rings are known to detach from the Agulhas Retroflection south of Africa in the vicinity of $15^{\circ} \mathrm{E}$ to $21^{\circ} \mathrm{E}$ and $37^{\circ} 30^{\prime} \mathrm{S}$ to $40^{\circ} \mathrm{S}$ (Lutjeharms and Ballegooyen, 1988; Lutjeharms and Valentine, 1988) and are known to contribute warm salty water to the South Atlantic Ocean and influence the Meridional Overturning Circulation (Gordon, 1985; Duncombe Rae, 1991; Duncombe Rae et al., 1996). Improved knowledge of their evolution is needed to understand their scales, translation speeds, and the role they play in the MOC.

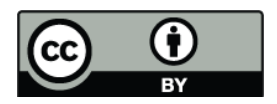

Correspondence to: S. Baker-Yeboah (sbaker@mit.edu)
Agulhas rings in the Agulhas Basin near the formation region off of South Africa can have mixed barotropicbaroclinic velocity structure (van Aken et al., 2003), as can some of those in the Cape Basin beyond the Agulhas ridge system (Baker-Yeboah, 2008). After formation, these eddies continue to adjust as they interact with local topography and other eddies, e.g., Agulhas rings can split as they interact with the Erica seamount (Arhan et al., 1999; Baker-Yeboah, 2008) or with cyclonic eddies (Baker-Yeboah, 2008). In addition, Agulhas rings can interact with the western continental slope along southern Africa. The interplay of such deep reaching Agulhas rings with the continental slope and shelf is important in understanding not only the different Agulhas rings that populate the eastern branch of the South Atlantic MOC but also in understanding the dynamics of the Benguela upwelling regime.

The interaction of an eddy with continental slopes and shelves has been addressed in the literature, and such interactions are known to influence cross-shelf exchange. Smith and O'Brien (1983) show planetary and topographic $\beta$ dispersive effects can result from such an interaction and can lead to an asymmetric distribution in eddy structure, which gives the eddy a nonlinear self-advective propagation tendency that can be greater than the planetary and topographic $\beta$-effects. Numerical studies by Smith (1986) show that anticyclones with weak lower layer co-rotating structure quickly evolve into upper-layer features and propagate independently of local topography, while anticyclones with non-negligible lower layer co-rotating structure can advect water offshore. Reducing the complex dynamics of eddy-slope interaction by using a simple barotropic contour dynamics model for an ideal vortex and a step topography, Wang (1992) captures four aspects of the eddy-slope interaction process: eddy induced cross-slope exchange, generation of a counter-rotating topographic eddy, altered eddy propagation tendency, and topographic wave generation. These factors drive cross-shelf exchange. 
Further studies by Shi and Nof (1993); Sanson and van Heijst (2000); Sutyrin et al. (2003); Frolov et al. (2004); An and McDonald (2005) and Tenreiro et al. (2006) also highlight the importance of a counter-rotating eddy in the eddyslope interaction process. Shi and Nof (1993) examine the process of a violent eddy-wall collision using contour dynamics and find that the parent eddy can split into two eddies that propagate along the wall-like boundary in opposing directions under the image effect; the parent eddy carries the core water properties, while the counter-rotating eddy comprises fluid from along the rim of the parent eddy. Sutyrin et al. (2003) and Frolov et al. (2004) used a two-layer, intermediate equation model on the $\beta$-plane to study Gulf of Mexico Loop Current Eddy interactions with the continental boundary shelf-slope region. Sutyrin et al. (2003) suggest that the $\beta$-effect drives deep cyclonic circulation at the trailing edge of the parent LCE (an anticyclonic eddy) and that together the eddies push onto the continental slope where the deep cyclonic eddy is dispersed by topographic Rossby waves. They find that the eddy propagation was governed by a combination of the $\beta$-effect, the joint cyclonic eddy in the lower layer, and the image effect associated with the continental boundary. They also show the formation of a deep corotating anticyclonic eddy in the case of a continental slope backed by a shelf wider than the radius of the parent eddy. The roles of both deep eddies and off-shelf advection of potential vorticity in the upper layer were further investigated by Frolov et al. (2004). They found that off-shelf advection of potential vorticity in the upper layer plays a role in generating a cyclonic eddy in the upper layer which then interacted with the LCE. They also report the formation of deep eddies due to stretching and compression of the lower layer by the parent LCE of elliptic shape. A controlling parameter in their study was the width of the continental slope.

Unlike most of these studies, Wang (1992); Sanson and van Heijst (2000); An and McDonald (2005) and Tenreiro et al. (2006) show offshore propagating dipole eddies that evolve in association with an eddy-slope interaction process. Sanson and van Heijst (2000) used a barotopic finite difference model to simulate the evolution of an eastward propagating dipole that formed due to the interaction of an anticyclone with a western boundary continental slope and stress the importance of the interaction of barotropic vortices with coastal topography. Tenreiro et al. (2006) explored the interaction of a barotropic dipole with a step-like topography using laboratory experiments and a quasi-two-dimensional model. The barotropic dipole configuration will also be explored in the current study but for a Southern Hemisphere case. Wang (1992) and An and McDonald (2005) used a barotropic, quasigeostrophic, contour dynamics model with a semi-infinite escarpment topography. An and McDonald (2005) suggest offshore propagating dipoles will occur whenever an eddy or coastal current interacts with canyon and escarpment topographies. Wang (1992) used an $f$-plane and $\beta$-plane primitive equation model with an exponential topography to show that cross topography volume transport can originate from different parts of the slope as a function of topography and penetration distance of the eddy forcing. The current study will use two models: one similar to that of (Wang, 1992) and one similar to that of Sutyrin et al. (2003) and Frolov et al. (2004) to address the importance of a dipolelike heton collision with the slope and the generation of a counter-rotating upper-and-deep eddy along the slope. This counter-rotating eddy shelf-slope interaction process will be shown to play a role in linking the deep ocean and shelf region in the Benguela upwelling system.

Both anticyclonic and cyclonic eddies dominate the velocity field in the Cape Basin off Cape Town, South Africa. They interact with each other, merge, split, and change shape, as seen in hydrographic and satellite data, directvelocity measurements, model simulations, and pressuresensor equipped inverted echo sounder data (Arhan et al., 1999; Richardson et al., 2003; Boebel et al., 2003; Matano and Beier, 2003; Baker-Yeboah, 2008). Interestingly, an Agulhas ring is often accompanied by a cyclonic eddy in the Cape Basin, and when propagating together these counterrotating eddies support a mutual advection or "dipoleadvection" (Baker-Yeboah, 2008). Cyclonic eddies are shed into the South Atlantic south of Africa and are often instrumental in the formation of Agulhas rings (Lutjeharms et al., 2003). Indeed, baroclinic instability of a jet intrinsically involves opposite-signed surface and deep eddies which pull the developing ring away from the jet (cf., Meacham, 1991; Flierl, 1999). Previous studies by Boebel et al. (2003) suggest that cyclones can form within the Cape Basin along the African shelf, inshore of the Agulhas Current, and in the subantarctic region south of Africa, and they are generally small, $120 \mathrm{~km}$ in diameter, compared to Agulhas rings. Recent studies by Baker-Yeboah (2008) reveal that cyclonic eddies can have comparable scales to Agulhas rings and that they can exist along the continental slope of southern Africa in association with Agulhas rings.

The formation of these large cyclonic eddies is investigated in this study using numerical simulations of hetons. This investigation differs from that of Matano and Beier (2003) and Wang (1992), who used point vortices based on the work by Hogg and Stommel (1985). We use two closed regions of constant vorticity based on the work by Polvani (1991), and the dipole-like heton propagates perpendicular to the line of centers, rather than along the line of centers as in the work by Matano and Beier (2003).

Dipole-like heton dynamics can aid in onslope penetration of an Agulhas ring. Water from the Agulhas Current has been observed in the region of the shelf in association with a front and a high velocity jet. Bang (1973) reports observations of a warm water feature or intrusion of Agulhas Current water that formed a sharp front over the shelf break in the upwelling regime west of Cape Town and that was connected to colder upwelled water over the shelf. Bang and Andrews (1974) report a strongly baroclinic frontal zone near the shelfbreak 
that contain a strong equatorward jet with maximum velocity of $1.2 \mathrm{~m} / \mathrm{s}$ and suggest an association with the local wind forcing. Lutjeharms et al. (1991) observed a long $770 \mathrm{~km}$ filament that extended from the shelf in association with an Agulhas eddy near the Luderitz upwelling cell. Filaments are known to form in association with the elongation of an Agulhas ring and indicate tracer leakage (de Steur et al., 2004; Whittle et al., 2008). Such filaments can extend well in to the thermocline (de Steur et al., 2004) and can be related to dipole dynamics, as will be illustrated in the current study. A narrow continental slope connects to a broad shelf region off of Cape Town, South Africa (Fig. 1). The continental slope and mean depth give a similar topographic beta effect of $2.5 \times 10^{14}\left(\mathrm{~m} \mathrm{~s}^{-1}\right.$ associated with the western coast of southern Africa, which is similar to that reported in Smith and O'Brien (1983) and in Sanson and van Heijst (2000). We use observations presented in Baker-Yeboah (2008) in conjunction with numerical simulations to show that eddy-slope interaction provides a dynamical link between the slope waters, shelf waters, and the open ocean in the Benguela upwelling regime.

We begin with observational background in Sect. 2 and proceed with numerical experiments on counter-rotating vortices in one layer in Sect. 3 and counter-rotating vortices one in each layer in Sect. 4. Models are initialized with a system of counter-rotating vortices that propagate into the slope, and a brief description of each model is given along with model results. Section 5 presents a discussion of our results and conclusions are in Sect. 6.

\section{Observational background: continental-slope dipole structures}

We expand upon two case studies of Agulhas eddies from Baker-Yeboah (2008) in this section, Agulhas anticyclones A06 and A19. Agulhas eddies, like A06 and A19, can become attached to the continental slope between $32.5-36.5^{\circ} \mathrm{S}$ where the water depth ranges from $2000-4500 \mathrm{~m}$. The resulting interaction affects waters along the slope and the shelf and leads to the formation of a mixed barotropic-baroclinic cyclonic eddy. These eddies encounter the continental slope under dipole dynamics, which is modeled in Sects. 3 and 4. A brief description of the evolution of these two eddies and how they affect the Benguela upwelling regime is given in this section. The data include pressure-sensor equipped inverted echo sounder (PIES) instruments, current meter moorings, and satellite data (Baker-Yeboah, 2008).

Figure 2 illustrates an upwelled water event on the shelf, between $33-36^{\circ} \mathrm{S}$, during the interaction of a cyclonic eddy and A06 near the continental slope. Water can be pumped onto the slope and influence the mass balance. The details of that process will not be addressed in this study. However, the cyclone played a role in advecting A06 shoreward as the two interact under dipole dynamics (modeled in Sects. 3 and

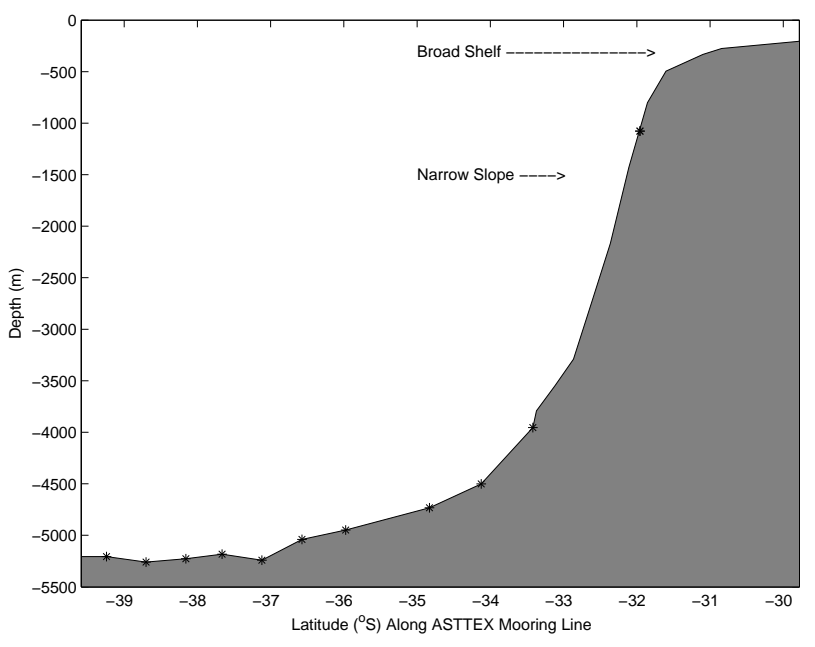

Fig. 1. Alongtrack section of continental bathymetry along Cape Town, South Africa. Asterisks show PIES sites.

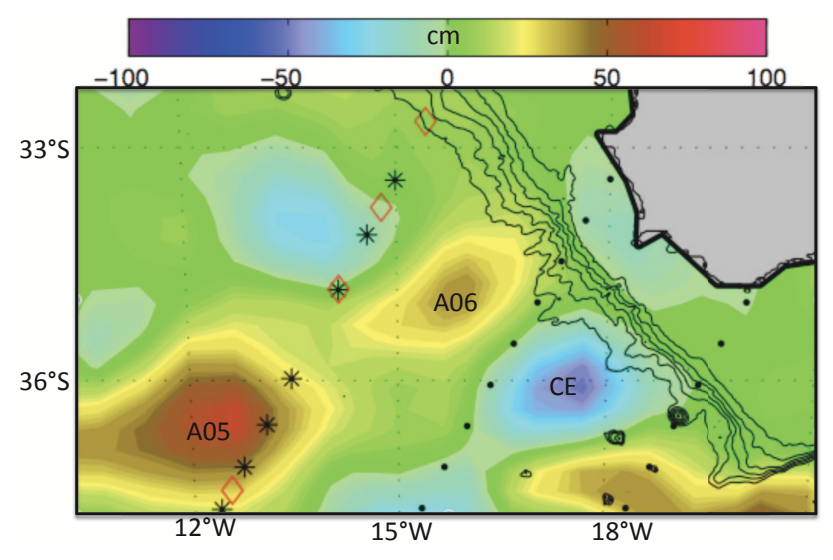

Fig. 2. Upwelling on the shelf and deep ocean eddies along the continental slope off of South Africa during 23 July 2003 in AVISO SSH anomaly map. Depth contours are plotted for 500-3000 m at an interval of $500 \mathrm{~m}$.

4). During July and August 2003, the upwelled water over the shelf moved west-northwest off the broad shelf region in association with A06.

Figures 3 and 4 include sequences of satellite maps that show the evolution of A06 and the cyclonic partner in the vicinity of the deep continental slope during July 2003January 2004. These counter-rotating eddies moved $\sim 50 \mathrm{~km}$ further onto the slope during the last two weeks of July, before taking on an along-slope translation: equatorward in the case of A06 and poleward in the case of the cyclone. Both eddies behaved like wodons (Shi and Nof, 1994) during 30 July-27 August, translating along the slope over a distance of $\sim 75 \mathrm{~km}$, as the counter-rotating eddies intensified in both scale (by $50 \mathrm{~km}$ ) and amplitude (by $|8| \mathrm{cm}$ ). By the end of August, both became elongated in shape, in association with the slope. 

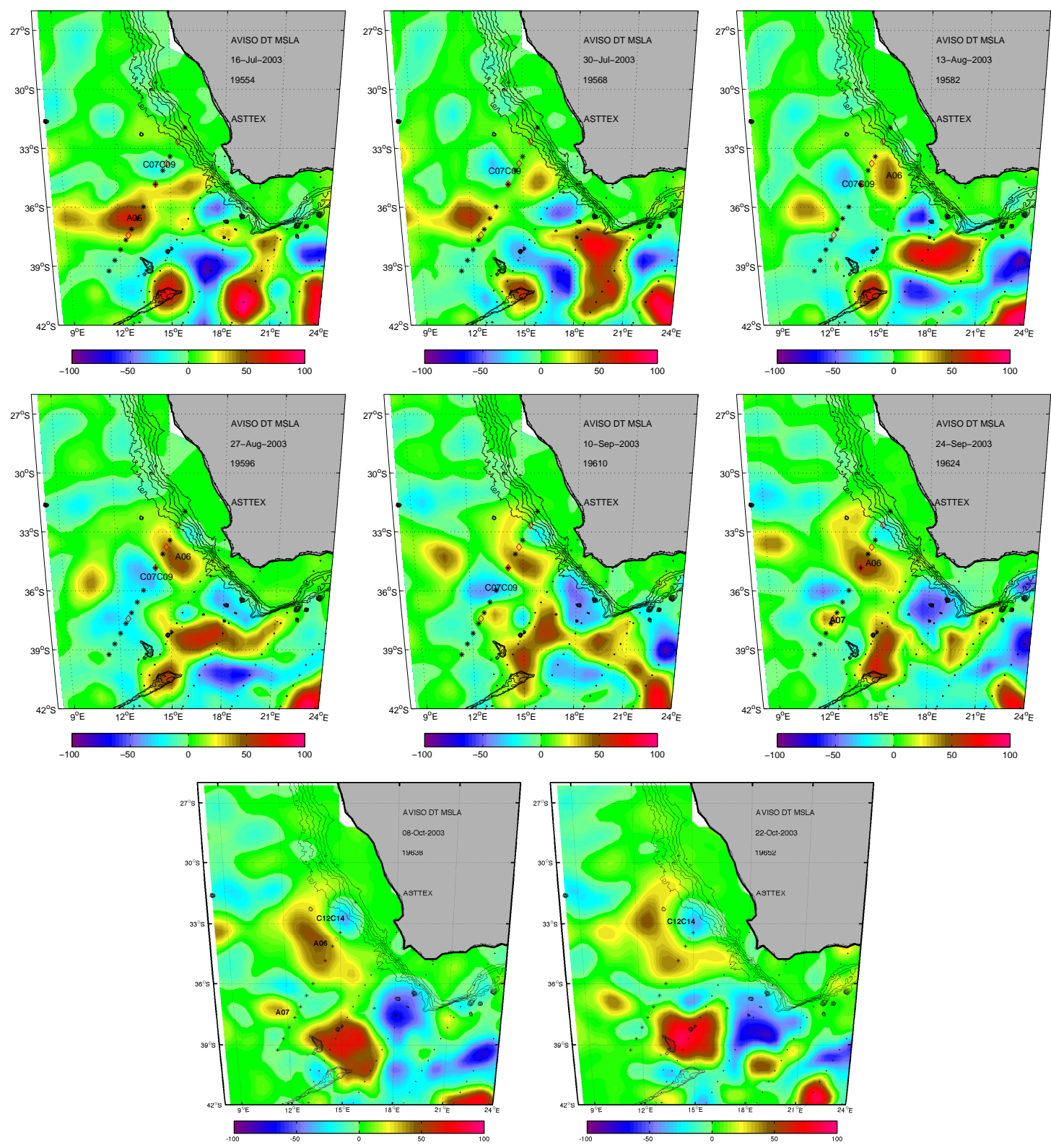

Fig. 3. Case I: maps of AVISO SSH sea level anomaly during the generation of a cyclonic eddy (C12C14, on the slope) by A06 during 2003.

During July and August 2003, the shelf water moved further offshore with A06 in the form of a new cyclonic eddy (Fig. 3). This new cyclone (C12C14) formed along the continental slope between $32^{\circ} \mathrm{S}$ and $33.5^{\circ} \mathrm{S}$, roughly 1 month after the July event of A06 and the cyclonic partner moving onto the slope. Together with A06 (the parent anticyclone), the two eddies form a dipole. This $3.7 \mathrm{~km} /$ day westnorthwestward propagating dipole survived for only 1 month (10 September-8 October). By 22 October, the large cyclone $\mathrm{C} 12 \mathrm{C} 14$ forced its way west-southwest, further away from the slope as it played a role in splitting A06 into two parts.
Figure 5a and $\mathrm{b}$ illustrates the structure of A06 during $\mathrm{Au}$ gust and September 2003. The elongated structure of A06 in the PIES baroclinic field was accompanied by a weak dipole in the deep pressure field. Note that the latter is rarely opposite to the baroclinic signal measured by the IES, indicating the presence of a strong contribution from the barotropic normal mode. The cyclone C09 was observed to rotate counterclockwise around A06 during August 2003 (see Fig. 3). Figure $5 \mathrm{c}$ shows the sum of the two quantities. Correspondingly, Fig. 5d shows total SSH variability from the alongtrack satellite data, since the instrument array was deployed along a satellite groundtrack. There was no PIES instrument between 

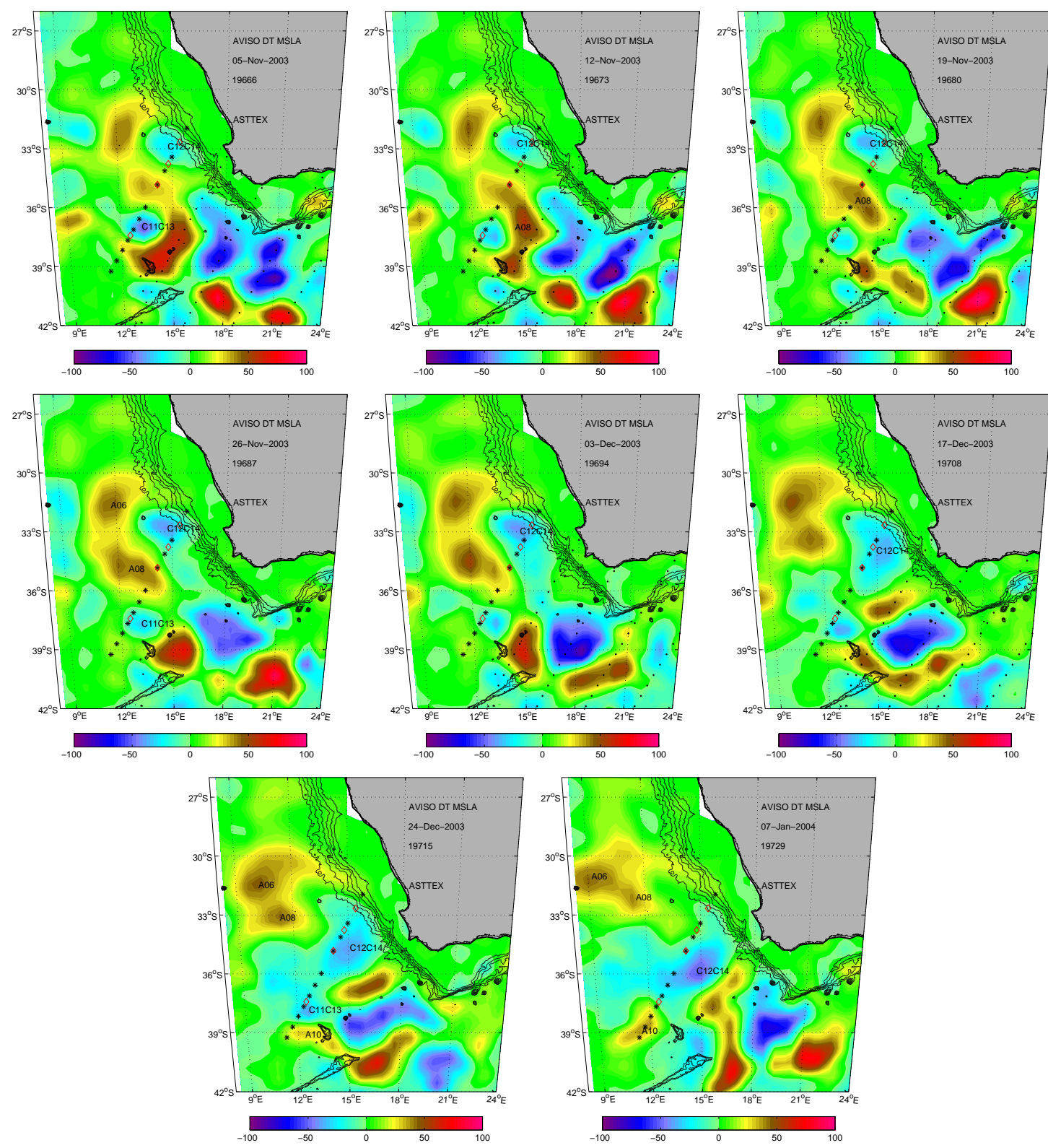

Fig. 4. Translation of cyclone C12C14 in maps of AVISO SSH sea level anomaly. Deep eddy L13 was coupled to C12C14 (see Fig. 6).

PIES-1 and PIES-2 - where the new cyclonic eddy moved onto the satellite groundtrack during September and October 2003 (compare Fig. 5c and d). So, the new cyclonic eddy C12C14 does not appear in Fig. 5a during September and October 2003. However, it was captured in the high (alongtrack) spatial resolution satellite data (Fig. $5 \mathrm{~d}$, between $32^{\circ} \mathrm{S}$ and $33.5^{\circ} \mathrm{S}$ ). During November 2003, when the new cyclonic eddy detached from A06 and the slope and took on a southwestward propagation as it moved across instrument sites (Fig. 4), C12C14 had a mixed baroclinic-barotropic structure. This vortex extended through the water column having both deep pressure (L13) and baroclinic (C12 and C14) structure (Fig. 6, from Baker-Yeboah et al., 2009). During October 2004, a similar Agulhas-eddy event also occurred between $32.5-36.5^{\circ} \mathrm{S}$ and is illustrated in Figs. 7 and 8. The mixed baroclinic and barotropic structure of the new cyclone is show in Fig. 9 (from Baker-Yeboah et al., 2009) as baroclinic cyclone C30 and deep cyclones L30 and L32. Such eddy structures consist of upper and deep ocean vortical motion. Key components of the pronounced dynamics of these heton-like Agulhas eddy dipoles are illustrated in the following section. 

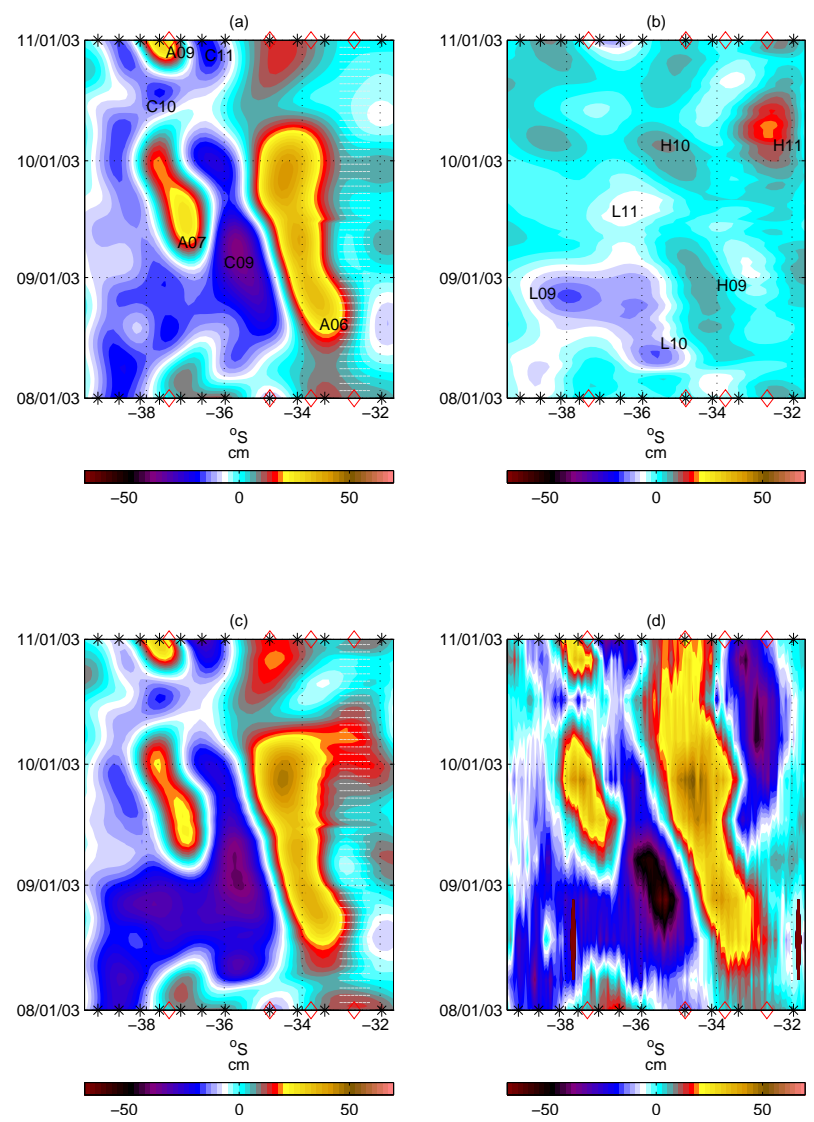

Fig. 5. Case I: time-space plots of (a) PIES baroclinic contribution to SSH (relative to bottom), (b) PIES bottom pressure contribution to SSH, (c) PIES total SSH, (d) Jason-1 SSH from AVISO for A06.

\section{Dipole numerical experiments}

Counter-rotating vortices interacting with topography will be studied using barotropic and two-layer-baroclinic models. We use both approaches on the $f$-plane to illustrate the similarities and differences in behavior.

\subsection{Barotropic dipole}

We begin with a contour dynamics, barotropic, quasigeostrophic model on the $f$-plane, based on Wang (1992). The governing equations are

$u_{t}+u u_{x}+v u_{y}-f v=-p_{x}$

$v_{t}+u v_{x}+v v_{y}+f u=-p_{y}$

$(u h)_{x}+(v h)_{y}=0$

for a barotropic, frictionless fluid. The depth is given by a topographic step

depth $=h_{1}, x<0 ;$ depth $=h_{2}, x>0$
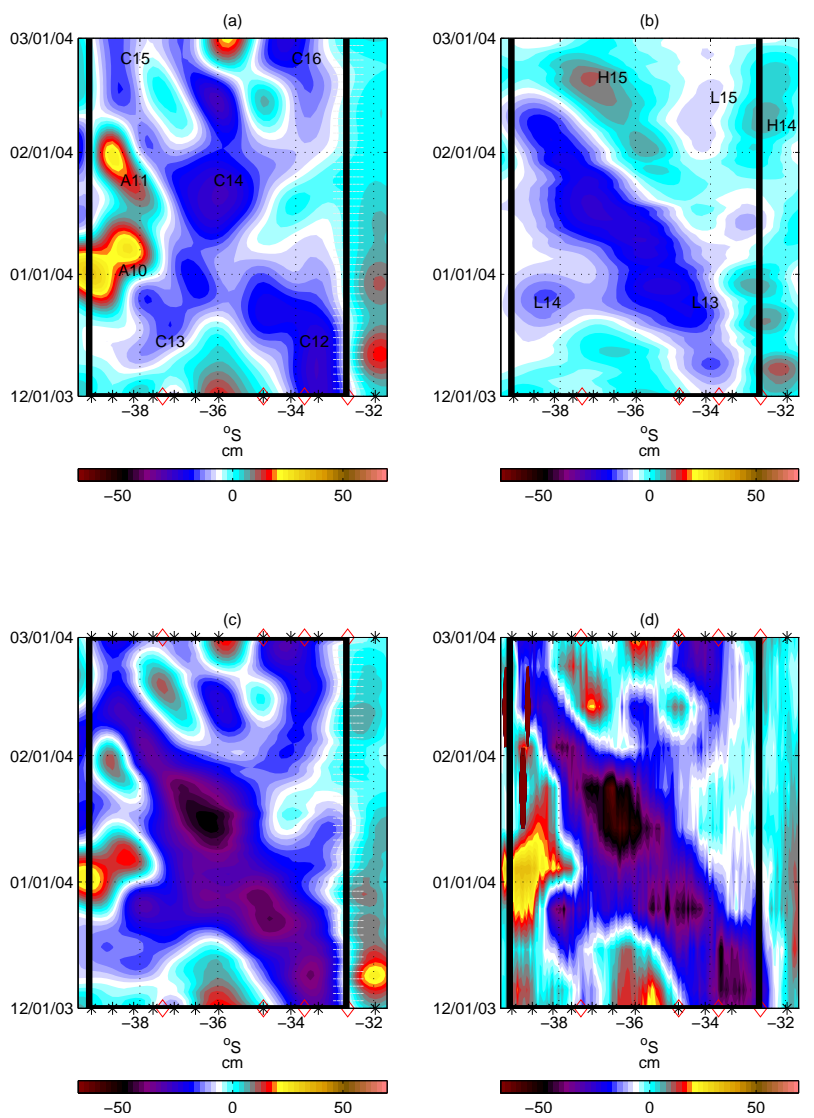

Fig. 6. Case I: time-space plots of (a) PIES baroclinic contribution to SSH (relative to bottom), (b) PIES bottom pressure contribution to SSH, (c) PIES total SSH, (d) Jason-1 SSH from AVISO for $\mathrm{C} 12 \mathrm{C} 14$. Figure from Baker-Yeboah et al. (2008).

that is aligned with $\mathrm{y}$-axis and is located at $x=0$. The matching conditions across the escarpment are

$u_{1} h_{1}=u_{2} h_{2}, v_{1}=v_{2}$

(Wang, 1992; Thompson, 1993) corresponding to finite vorticity (PV, potential vorticity, being conserved) and continuity of mass flux.

The system has two nondimensional parameters, the Rossby number $\epsilon=U / f_{o} L=q_{v} / f_{0}$ (with $q_{v}$ the value of the vorticity in the eddies) and the depth jump $\delta=\left(h_{1}-\right.$ $\left.h_{2}\right) / \frac{1}{2}\left(h_{1}+h_{2}\right) \equiv \Delta h / h$. In addition, the motion and development of the dipole will be determined by the ratio of the separation distance to the radius of each vortex, as well as the ratio of strengths and sizes of the vortices. Wang (1992) explored these different parameters, including order one depth variation and the quasigeostrophic limit $\delta \sim \epsilon \ll 1$. We consider only the QG case, so that we have only one parameter, $\Delta_{\text {top }}=\delta / \epsilon$ which is the ratio of the PV jump associated with the topographic PV step to that across the vortex boundary. This parameter characterizes when we expect to see filaments, when the image-like effect is more prevalent, 

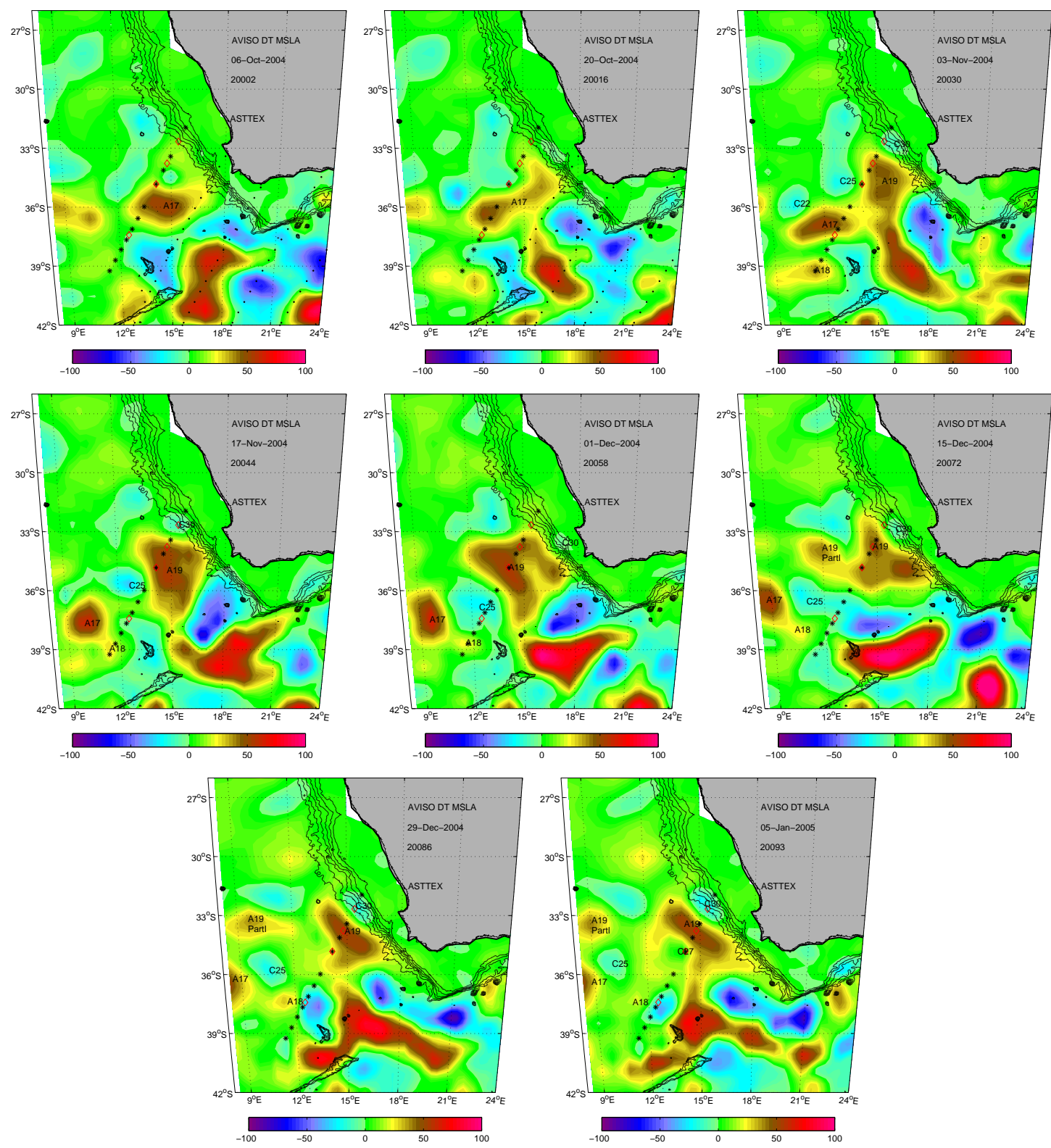

Fig. 7. Case II: maps of AVISO SSH sea level anomaly during the generation of a cyclonic eddy (C30, on the slope) by A19.

and when there is strong or weak off-shelf (or off slope) advection. We use vortices with radii equal to $2 R_{d}$, where the deformation radius $R_{d}$ is $30 \mathrm{~km}$.

Assuming the $\mathrm{PV}$ is piecewise constant implies that the streamfunction is related to the PV by

$$
\begin{aligned}
q & =\nabla^{2} \psi+\frac{f_{0} \delta h}{h} H(x)=q_{C} \chi_{C}(x, y, t)+q_{A} \chi_{A}(x, y, t) \\
& +\frac{f_{0} \delta h}{h} H(x-\eta)
\end{aligned}
$$

where $H$ is the Heaviside step function and $\eta(y, t)$ represents the boundary of the water originating in the shallow region. The characteristic functions $\chi_{C}$ and $\chi_{A}$ are higherdimensional analogues of the step function, being one when the point $(x, y)$ is within the cyclone's or anticyclone's area and zero outside. Initially, the eddies are circular with the same radius. The vorticity anomalies $q_{C}$ and $q_{A}$ are constants such that $q_{A}=-q_{C}$. In the QG limit, the matching conditions across the escaprment reduce to continuity of $\psi$ and $\psi_{y}$.

As in Wang (1992), we use the Green's function method to solve the above Poisson PV equation for the flow field, and we write the velocity on the vorticity contour (which is the boundary of a vortex or $\eta$ ) in terms of contour integrals along each boundary. The boundary points are treated 

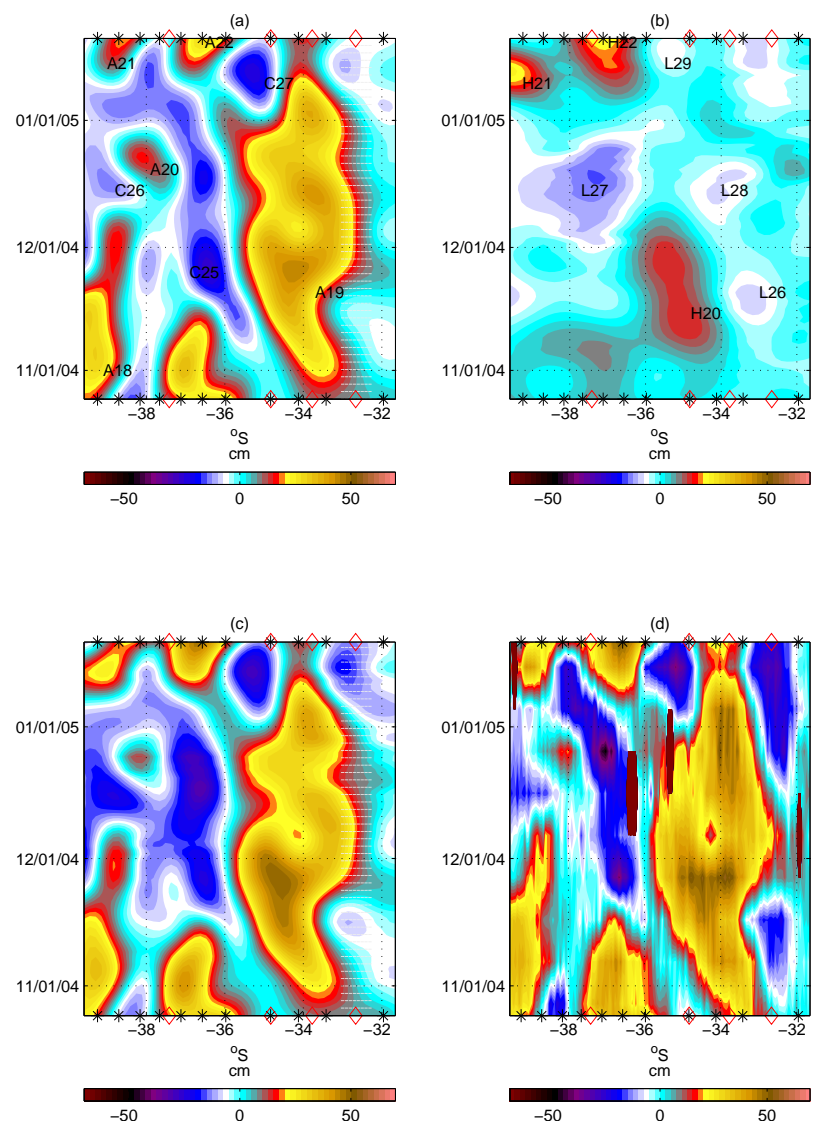

Fig. 8. Case II: time-space plots of (a) PIES baroclinic contribution to SSH (relative to bottom), (b) PIES bottom pressure contribution to SSH, (c) PIES total SSH, (d) Jason-1 SSH from AVISO for A19.

as lagrangian points and are advanced using the computed velocities. This "contour dynamics" method (Zabusky et al., 1979; Flierl, 1999) is essentially inviscid.

Figure 10 illustrates, for different $\Delta_{\text {top }}$ values, the process of vortex stretching and compression as the barotropic dipole collides into the escarpment. The black contour centered along the escarpment at the initial time is the boundary of the high PV fluid that originates on the shallow region. As the eddies advect one another shoreward they become more elongated because of the strain fields from the opposite member of the pair; we could have avoided this by starting with the dipole "V-state" (Wu et al., 1984; Polvani, 1988) in which vortices are elongated initially, but would not expect the topographic interactions to be significantly different.

The self-advecting dipole structure approaching the shelf begins to perturb the fluid above the escarpment at a distance of about $d=2 r$ away from the slope, where $r$ is the mean radius of the eddy. This dipole flow pushes water onshore at the centerline and offshore on both sides (see the small $\Delta_{\text {top }}$ case in Fig. 10); however, the topographic or escarpment waves propagate southward for this configuration $(f<0)$, so that the northern (central) lobe interacts more strongly with
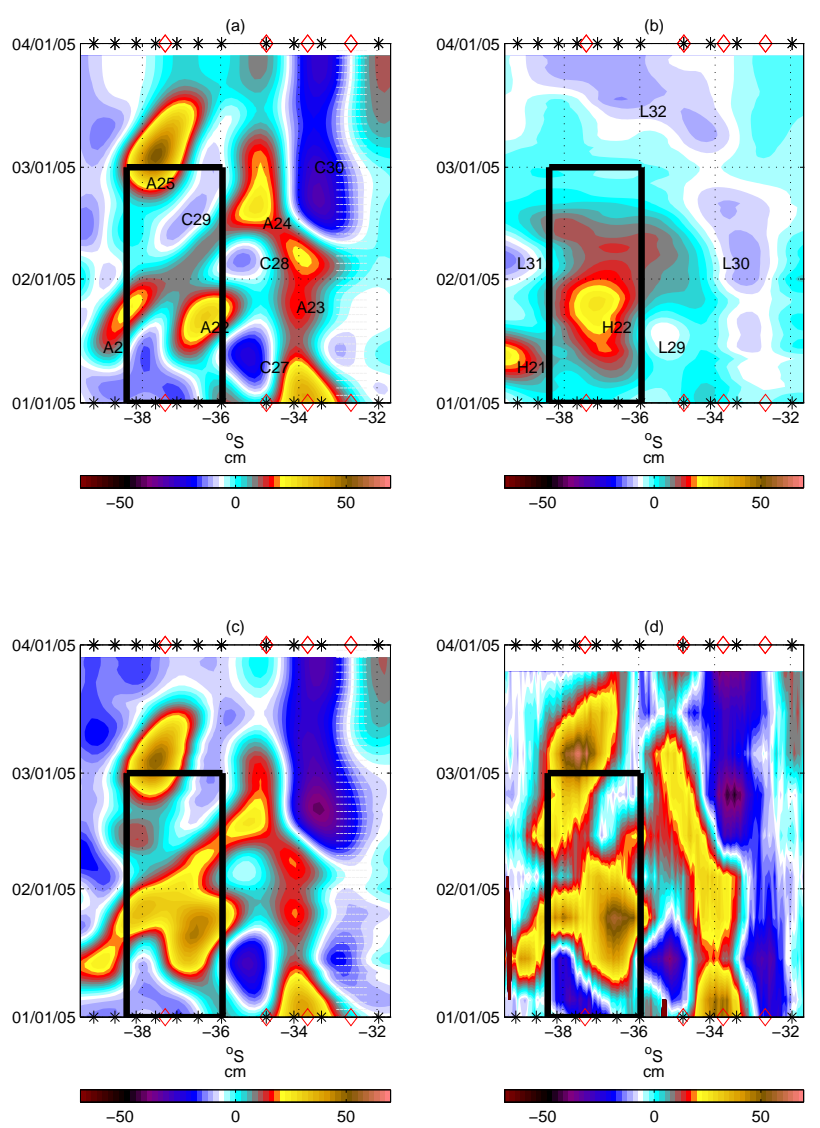

Fig. 9. Case II: time-space plots of (a) PIES baroclinic contribution to SSH (relative to bottom), (b) PIES bottom pressure contribution to SSH, (c) PIES total SSH, (d) Jason-1 SSH from AVISO for C30. Figure from Baker-Yeboah et al. (2008).

the anticyclone (cyclone). For small $\Delta_{\text {top }}$, the dipole penetrates into the shallow region, carrying a band of offshore fluid with it; an equal amount of onshore fluid is pushed into deeper water, but does not spin up strongly, since the depth change is small. Such dipole penetration results are consistent with those presented in Tenreiro and Sanson (2006), but for a Southern Hemisphere case as the anticyclone causes an equatorward deflection. Important characteristic behaviors visible in Fig. 10 include the 1) collapse or continuation of the structure, 2) on- and off-slope or shelf advection, 3) filamentation, and 4) formation of a counter-rotating vortex.

The vortex-lobe interactions, visible when $d \sim r$, push the anticyclone offshore and northward, while drawing the cyclone onshore and southward. The anticyclonic vortex continues to advect the high PV fluid seaward, with vortex stretching generating strong cyclonic circulation. Part of the fluid gets advected seaward and around the anticyclone as a filament. For $0.2<\Delta_{\text {top }}<3$, most of the fluid forms a closed PV anomaly of opposite sign vorticity - a new cyclonic circulation. The case $\Delta_{\text {top }}=1$ resembles the observations in that a new cyclone spins up quickly and forms a new dipole 

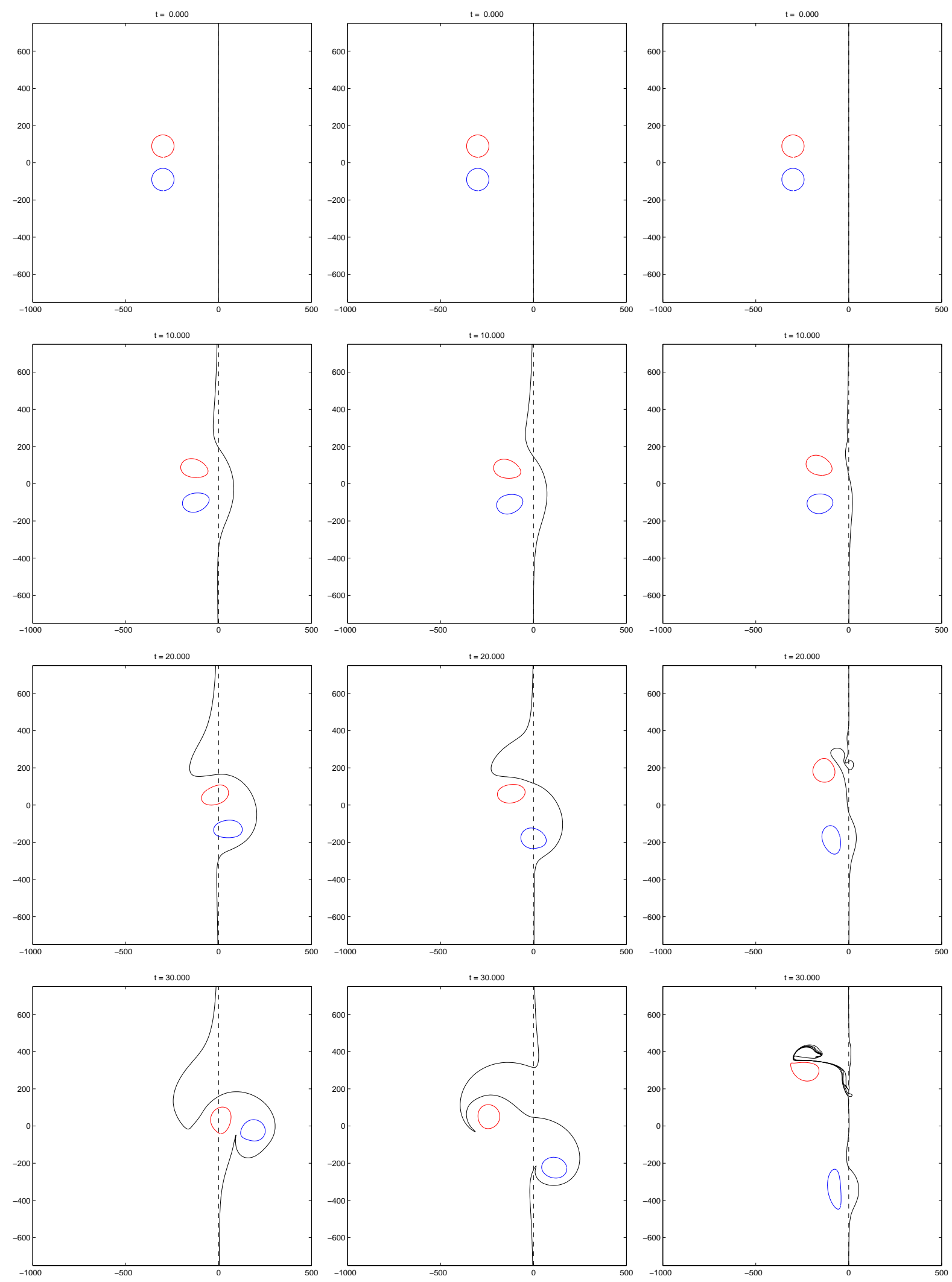

Fig. 10. Quasi-geostrophic $f$-plane contour-dynamics model of a barotropic dipole colliding with a continental slope: anticyclone (cyclone) in red (blue). Recall, these are Southern Hemisphere cases, so that the reotation is counter-clockwise (clockwise). Deep to shallow water from left to right. Panels: $\Delta_{\text {top }}=[0.1$ (left), 0.2 (middle), 1.0 (right)] for time steps $t=[0,10,20,30]$. 

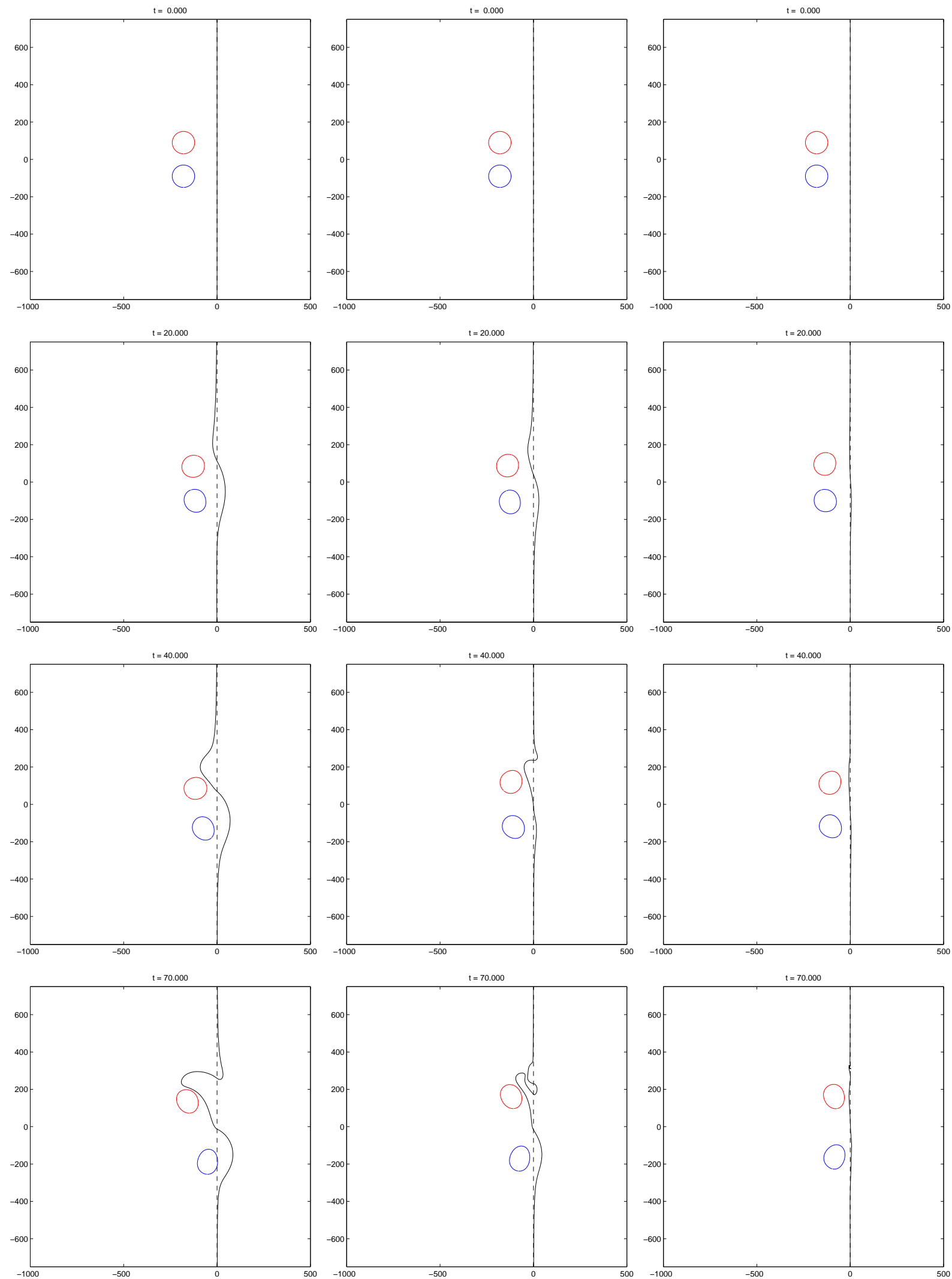

Fig. 11. Two layer, quasi-geostrophic $f$-plane contour-dynamics model of an upper layer dipole colliding with a continental slope: anticyclone (cyclone) in red (blue). Deep to shallow water from left to right. Panels: $\Delta_{\text {top }}^{*}=[0.1$ (left), 0.2 (middle), 1 (right)]. 

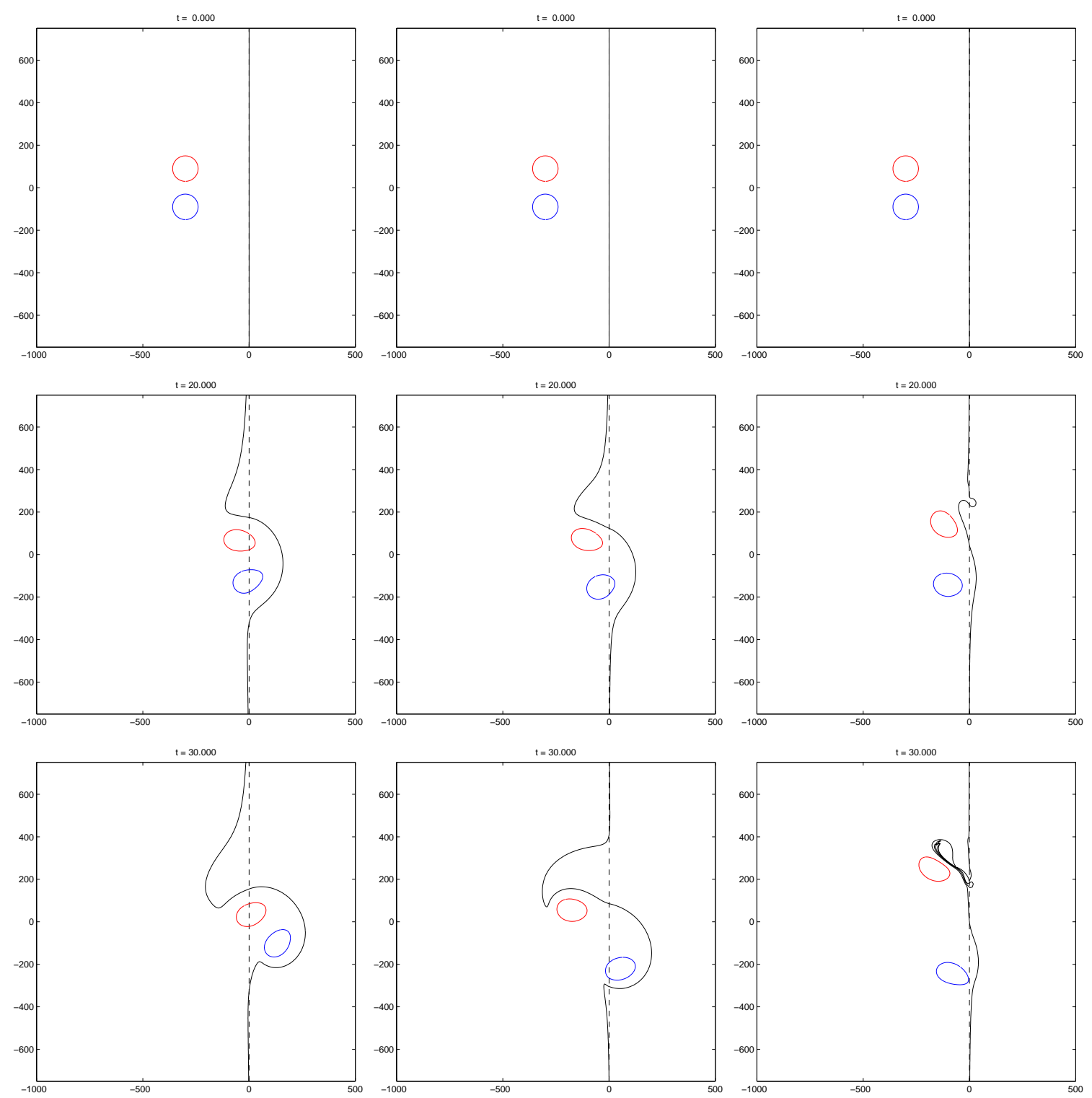

Fig. 12. Two layer, quasi-geostrophic $f$-plane contour-dynamics model of a lower layer dipole colliding with a continental slope: anticyclone (cyclone) in red (blue). Deep to shallow water from left to right. Panels: $\Delta_{\text {top }}^{*}=[0.1$ (left), 0.2 (middle), 1 (right) .

structure in association with the parent antiyclone and begins to move away. This new dipole propagates offshore but in a circular path so that the feature will again hit the shelf. This circular trajectory is due to the asymmetric vorticity distribution in the counter-rotating vortices and is unlike that in the observations, which suggest symmetric vortices at the onset that move along a trajectory perpendicular to their line of centers.

On- and off-shelf advection decreases as $\Delta_{\text {top }}$ increases. In cases of very strong topography $\left(3 \leq \Delta_{\text {top }} \leq 10\right)$, after the dipole collapses both eddies move along the topography (image-like effect), with little to no filamentation, or offshelf (on-shelf) advection. So, for large $\Delta_{\text {top }}$, the escarp- ment acts effectively as a wall, and the vortices separate and move north and south just as a head-on collision with the image dipole results in the vortices changing partners. In this model approach, the source water in the new cyclone is the shelf; in Sect. 4, we show that water can also be drawn from the slope, rather than just the shallow region, when the topography is gradual.

\subsection{Single layer dipoles in a two layer model}

We have examined the same problem in a two-layer model with both vortices in the upper layer and the topography in the deep layer. 

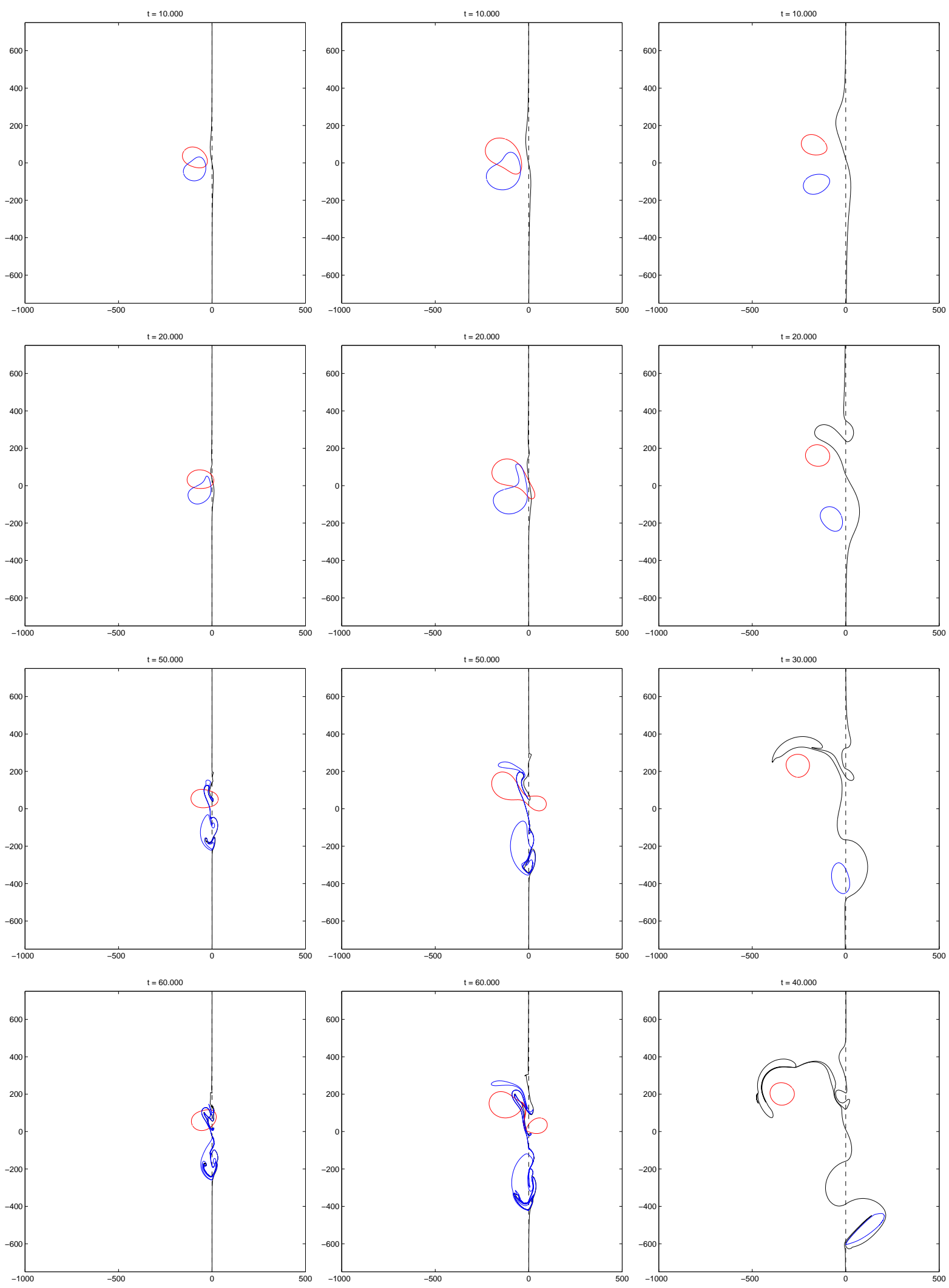

Fig. 13. Two layer, guasi-geostrophic $f$-plane contour-dynamics model of a heton (left panels, $\Delta_{\text {top }}^{*}=0.5$; middle panels, $\Delta_{\text {top }}^{*}=0.5$ but $R_{\text {eddy }}=90 \mathrm{~km}$ ) colliding with a continental slope compared to a barotropic dipole (right panels and $\Delta_{\text {top }}=0.5$ ). Anticyclone (cyclone) in red (blue). Deep to shallow water from left to right. 
Table 1. Numerical experiments of heton-like dipoles on the $f$ plane, which collapses at the slope or moved across the slope. Off (on) slope advection given in terms of area of the anticyclonic vortex A. The cyclonic vortex (C) has a tendency to advect water on-slope, while A advects water off. No(Yes): N(Y).

\begin{tabular}{llllll}
\hline$\Delta_{\text {top }}$ & $\begin{array}{l}\text { Collapse } \\
\text { At Slope }\end{array}$ & $\begin{array}{l}\text { Off }(\mathrm{On}) \\
\text { Slope } \\
\text { Advection }\end{array}$ & $\begin{array}{l}\text { Area } \\
() \times \mathrm{A}\end{array}$ & $\begin{array}{l}\text { Filament } \\
\text { From }\end{array}$ & New C \\
\hline 0.01 & $\mathrm{~N}$ & $\mathrm{~N}(\mathrm{Y})$ & $(0)$ & $\mathrm{C}$ but thin & $\mathrm{N}$ \\
0.05 & $\mathrm{~N}$ & $\mathrm{Y}(\mathrm{Y})$ & $(2 / 3)$ & $\mathrm{C}$ but thin & $\mathrm{N}$ : protrusion \\
0.10 & $\mathrm{~N}$ & $\mathrm{Y}(\mathrm{Y})$ & $(1)$ & C but thin & $\mathrm{Y}$ : slope water \\
0.20 & $\mathrm{Y}$ & $\mathrm{Y}(\mathrm{Y})$ & $(2 / 3)$ & $\mathrm{C}$ but thin & Y: slope water \\
0.50 & $\mathrm{Y}$ & $\mathrm{Y}(\mathrm{N})$ & $(1 / 4)$ & $\mathrm{C}$ but thin & Y: slope water \\
& & & & & and filament \\
\hline
\end{tabular}

The PV has similar form as Eq. (5) but related to the streamfunction for the two layers $\psi_{1}$ and $\psi_{2}$ by

$$
\begin{aligned}
& q_{1}=\nabla^{2} \psi_{1}-\frac{d_{2}}{d_{1}+d_{2}} R_{d}^{-2}\left(\psi_{1}-\psi_{2}\right) \\
& q_{2}=\nabla^{2} \psi_{2}-\frac{d_{1}}{d_{1}+d_{2}} R_{d}^{-2}\left(\psi_{2}-\psi_{1}\right)+f_{0} \frac{\Delta h}{d_{2}} H(x)
\end{aligned}
$$

where $\Delta h$ still represents the height of the topographic step. The upper and lower layer thicknesses, $d_{1}$ and $d_{2}$, satisfy $d_{1}+d_{2}=\left(h_{1}+h_{2}\right) / 2$. We now have $\delta^{*}=\Delta h / d_{2}$, so that a given $\Delta_{\text {top }}^{*}$ top value represents a slightly smaller $\Delta h$ than in Sect. 3.1.

We shall refer to the step here as the "slope" rather than the "shelf" since the topography is only in the lower layer. We use a depth ratio of $d_{1} / d_{2}=0.2$ and vortices with radii equal to $2 R_{d}$. Results (Fig. 11) were similar (Fig. 10) for medium to large $\Delta_{\text {top }}^{*}$ values. At large values, water drawn off the slope spins up to become a strong cyclone and pairs with the anticyclone to propagate offshore as a dipole. Also, the path is circular so that the feature will again hit the slope. In general, the $\Delta_{\text {top }}^{*}$ values were smaller for the two layer experiments than those for the barotropic model and the response time was longer. The two primary differences occur for small topographic steps and in on- and off-slope advection. For small $\Delta_{\text {top }}^{*}$ values, the dynamics of motions in a two layer model with bottom topography retains significant interaction between the upper and deep ocean. But the vortex impulse is weaker, so that the penetration across the topography is less and the anticyclone does not generally cross the slope (at $x=0$ ) unless $\Delta_{\text {top }}^{*}<0.05$. The on and off slope PV driven advection is weaker than in the case of a barotropic dipole examples.

Similarly, we examined the same problem, but with both vortices in the deep layer. The evolution of the dipole crashing into the topography (Fig. 12) remains the same; however, the off and on slope advection is greater than that for the upper layer dipole in the same two layer model. With such large vortices (much larger than $R_{d}$ ) extending through most $(5 / 6)$ of the water column, the barotropic mode dominates and the topographic interaction is qualitatively similar to the barotropic dipole examples, except that water is pulled off and pushed onto the deep slope.

\section{Heton-like dipole numerical experiments}

For the case of counter-rotating vortices, with motion of each vortex residing in a separate layer, we use a "heton" pair (Hogg and Stommel, 1985; Polvani, 1991, except the layer depths are unequal) to illustrate the dipole behavior. However, the vortices do not overlap completely, so that there is a dipole moment propelling them westward.

\subsection{An $f$-plane Heton-like dipole}

The more interesting case for the Agulhas eddies involves an upper layer anticyclone and a lower layer cyclone, since Agulhas eddies can have cyclonic partners (Baker-Yeboah, 2008). Figure 13 illustrates the behavior of a heton that crashes into a slope using again the step-like topography in the deep layer. Notice that these counter-rotating eddies are not aligned (one directly over the other). Because of the different form of coupling between the counter-rotating vortices, they react differently when they encounter the topography. In the two heton cases, the deep cyclone pushes the upper anticyclone over the topography. For the previous cases, the initial circles are close enough to the steadily propagating V-states that the contours just wobble as the dipole propagates; for the heton case, however, the boundaries of the patches distort significantly with filaments drawn around the other member of the pair. We have started the eddies closer to the topography so that they begin interacting with it before too much distortion has occurred.

The heton causes far less on and off slope (or shelf, in the barotropic case, Fig. 10) advection compared to the upper or deep layer dipoles (Figs. 11 and 12). In terms of surface area, on (and off) slope advection due to the heton never exceeds one times the area of the anticylone, where as for the other three structures it sometimes exceeds two times the area of the anticylone. Water in the heton case is moved off the slope below the anticyclone; the source water in the new cyclone is the shallow region, along with a minute contribution from the cyclone, which forms filaments as it begins to move along the slope.

At the slope, the heton structure behaves differently depending on the strength of the bottom topography compared to the strength of the vortices (Table 1). The heton collapses at the slope when the PV jump associated with the topography exceeds that across the shallow vortex by about $20 \%$, i.e., when it becomes greater than the deep vortex PV jump. When the structure collapses at the slope, the deep 
eddy interacts strongly with the topography, moving southward away from the upper layer eddy and is drawn partially into the shallower water. As in the previous cases, the image effect plays the role of moving the deep eddy along the slope, when the bottom topography acts like a wall. The upper layer eddy does not move along the boundary but creates only small perturbations to the deep fluid at the edge of the escarpment and advects water off the slope below it, with the distubance propagating rapidly away.

The heton collapses more quickly for increasing $\Delta_{\text {top }}$ (see Table 1), whereas the advancing heton remains coherent, continuing onto the slope with shoreward penetration of its water, in the case of small $\Delta_{\text {top }}$. Overall, the anticyclone advects more water off the slope for $0.01 \leq \Delta_{\text {top }}<0.1$ and less water for $0.1<\Delta_{\text {top }} \leq 0.5$, which is related to the increasing influence of the slope compared to that of the vortex.

For these large vortices or eddies, the dominance of the barotropic mode implies the topographic interaction resembles the first example; however, the steady propagating states with overlapping upper and lower layer PV patches (Polvani, $1988)$ tend not to be stable. For vortices $\left(R \geq 3 R_{d}\right)$, the anticyclone splits along the topography such that part is left along the slope (Fig. 13, right panel); such splitting occurred in the case of A19 (see Sect. 2). Such parts provide additional PV along the slope and so may increase the number of dipoles from the slope/shelf region.

\subsection{A $\beta$-plane heton-like dipole}

Next, we use a baroclinic-two-layer, intermediate equation model on the $\beta$-plane, based on Frolov et al. (2004). The beta-effect is known to generate predominantly westward drift of both cyclonic and anticyclonic eddies (e.g., Sutyrin and Flierl, 1994), thus pushing Agulhas eddies away from Benguela continental slope. In order to consider the eddy dynamics with the beta-effect and finite-amplitude smooth sloping topography we use a two-active-layer model based on intermediate equations described in Frolov et al. (2004). The parameters of the model are density difference between upper and middle layer $\left(\rho_{2}-\rho_{1}\right) / \rho_{1}=10^{-3}$, density difference between middle and lower layer $\left(\rho_{3}-\rho_{2}\right) / \rho_{1}=10^{-3}$, thickness of upper and middle layers $d_{1}=1 \mathrm{~km}, d_{2}=2 \mathrm{~km}$ (the lower layer is assumed motionless) maximum topographic slope in the middle layer $s=10^{-2}$ decreasing towards vertical boundary in the upper layer, the Coriolis parameter $f_{0}=-$ $7 \times 10^{-5} \mathrm{~s}^{-1}$, its meridional gradient $\beta=2 \times 10^{-11} \mathrm{~m}^{-1} \mathrm{~s}^{-1}$. The velocity in the intermediate model is represented by two orders of asymptotic expansion in the Rossby number while the depth variation in each layer can be arbitrary. Correspondingly, Lagrangian conservation of PV is satisfied for the ratio of absolute vorticity to the layer thickness. Furthermore, this model incorporates an exponential continental slope topography (see Frolov et al., 2004).

Similar to the model setup in Sect. 4.1, a baroclinic vortex dipole is initialized as a heton with compact anticyclonic
PV anomaly in the upper layer and cyclonic PV anomaly in the middle layer, which is prescribed by formulas given in Frolov et al. (2004). In this model approach, the PV contours overlap as in Fig. 13, but with smaller distance between the centroids $\left(<0.5 R_{\text {eddy }}\right)$, giving the heton slightly higher self propagation velocity.

When this strong heton structure approaches the slope ( $t=40$, Fig. 14), the middle layer PV core is clearly seen near the slope. Later the cyclonic PV anomaly in the middle layer collapses, generating strongly nonlinear topographic Rossby waves propagating poleward; at $t=60$ the original PV anomaly became very small due to dispersion and diffusion. Unlike previous cases, it is not seen later in time, leaving only noticable perturbations of along-slope PV contours, unlike all previous cases.

The anticyclonic circulation penetrating from the upper layer advects water off-slope forming a new cyclonic anomaly in the middle layer equatorward of the anticyclone, as in previous cases. The upper layer anticyclone propagates away from the slope due to both the beta-effect and the cyclonic anomaly in the middle layer dynamically connected to the parent anticyclone. This process of vortex stretching as water is drawn off-slope enhances cross-topography transport and supports the formation of a deep cyclonic eddy.

\section{Discussion}

In addition to the seamounts and the Agulhas ridge system, the continental slope topography also affects the structure of Agulhas rings. Model results of a barotropic eddy with bottom topography show that a barotropic anticyclonic eddy can interact with the shelf and form a cyclonic partner on the $f$ plane, similar to that of Wang (1992). This is also the case for baroclinic dipole in a two layer model on the $f$-plane and on the $\beta$-plane. The $\beta$-effect is not required for formation of the cyclone.

In the vicinity of a continental topography, heton-like dipole eddy structures provide a mechanism of shoreward propagation of water from the deep ocean and seaward propagation of water from the slope and shelf region. The creation and destruction of relative vorticity can enhance open ocean and shelf exchange, as well as couple the upper and deep ocean. Such coupling is perhaps stronger in the ocean than in the three models, which generally lack a comparable amount of water or vorticity in the newly generated cyclone, so that the dipole cannot move away as a symmetric structure. However, unlike the nonlinear dispersion tendency, the nonlinear dipole tendency can induce shoreward, seaward, poleward, or equatorward propagation of an Agulhas anticyclone. Thus, the evolution of Agulhas anticyclones involves dynamical responses with surrounding fluid and topography in the form of both eddy-eddy advection and eddytopographic-slope advection. 
Agulhas rings near the formation region off of southern Africa can have mixed barotropic-baroclinic velocity structure, as illustrated in van Aken et al. (2003). Given their deep structure, Agulhas eddies can excite the formation of deep cyclonic eddies in the Cape Basin as they interact with the continental slope. Observations presented in Sect. 2 show two cases of new cyclonic eddies that form as a result of an Agulhas anticyclone interacting with the continental slope: satellite observations show the surface signature of the eddy field near the coast of southern Africa and in situ observations reveal the upper and deep ocean mixed barotropicbaroclinic structure. Although Agulhas rings can have mixed deep structure after formation in the Agulhas Basin, they have to navigate around the seamounts and across the Agulhas ridge to reach the Cape Basin and may lose part of their deep structure. Part of the response to that topography is splitting (see Sect. 1). However, when in the vicinity of the deep slope topography, anticyclones with weak lower layer co-rotating structure can quickly evolve into upperlayer features (Smith, 1986). Recent observations (BakerYeboah et al., 2009; Baker-Yeboah et al., 2010) show Agulhas eddies and cyclones that cannot be described as equivalent barotropic (i.e., $\psi_{2} \neq \alpha \psi_{1}$ for any non-negative number $\alpha$ ). Furthermore, deep reaching Agulhas eddies (as show herein) can encounter the slope via dipole dynamics which can result in additional dipole generation: some stable and some unstable to local eddy forcing and other tendencies like the $\beta$-effect.

The formation of a counter-rotating partner (illustrated in Sects. 2, 3 and 4) supports mixing of shelf and slope water, due to the eddy-slope interaction process. The resulting cyclonic eddy takes on a mixed structure in the upper and deep water column; as presented in Sect. 2, joint baroclinic eddy C04 and deep eddy L03, joint baroclinic eddy C12C14 and deep eddy L13, and joint baroclinic eddy C30 and deep eddy L30 (same as L32) each formed in a similar manner - during the interaction of an Agulhas anticyclone with the continental margin. Thus, the eddy-slope interaction process provides a dynamical link between water along the shelf, slope, and in the open ocean in the Benguela upwelling regime. Further, this process can increase the number of cyclones in the Cape Basin.

Although we used simplified step-like topography in the contour dynamics model, the results capture many of the basic processes revealed in the observations: 1) on-slope and off-slope (and shelf) vortex advection, 2) vortex driven filamentation, and 3) formation of a counter-rotating vortex. The numerical experiments also highlight the importance of the ratio of the PV jump associated with the topography to that across the vortex boundary. Similar eddy-slope interaction processes have been studied by Wang (1992) and (Sutyrin et al., 2003). The eddy-slope interaction can lead to strong wave dispersion, in which the shelf-ring interaction can generate topographic RWs (Swaters and Flierl, 1991; Sutyrin et al., 2003).
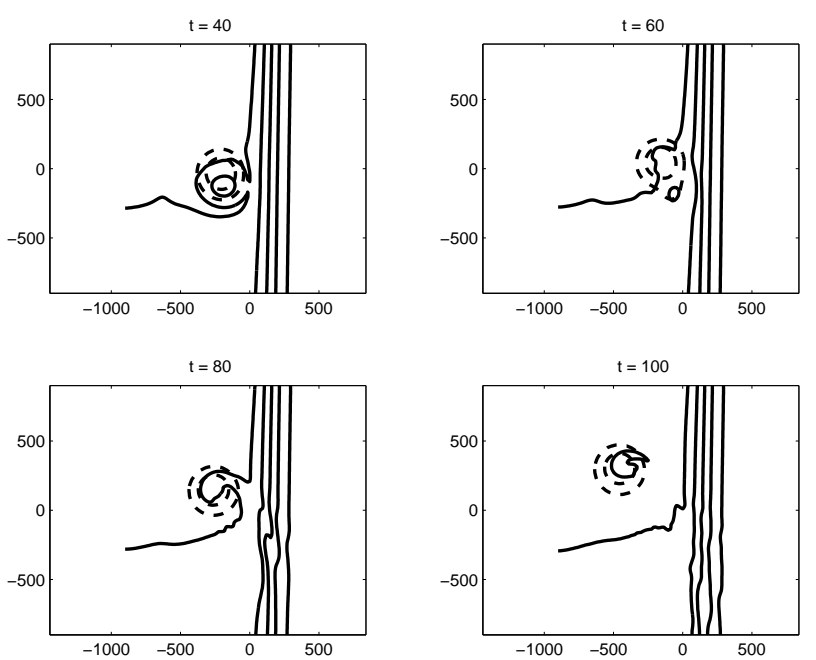

Fig. 14. Geostrophic $\beta$-plane model of a baroclinic heton-like dipole colliding with a continental slope in the lower layer: upper layer anticyclone pressure contour (dashed) and middle layer cyclone potential vorticity contour (solid).

Planetary and topographic $\beta$-effects are important for a deep reaching, mesoscale, eddy structure. Planetary $\beta$ appears to play an important role in the separation and westward translation of the newly formed eddy-slope generated dipole structure. The evolution of the heton structure on the $\beta$-plane as it collides with a continental slope (modeled by an deep continental slope with an intersecting interface displacement) produces radiating topographic Rossby waves in addition to filaments and vortex advection and stretching. After collision, the lower layer cyclonic eddy disperses into topographic Rossby waves. The anticyclonic vortex continues to evolve on the slope, to advect the high PV fluid seaward, which then forms a new cyclonic eddy in the deep layer. Part of the fluid gets advected seaward in the deep layer and around the anticyclone as a thin filament while most of the fluid forms a closed PV anomaly of opposite sign: a new deep cyclonic circulation. Thus the topographic $\beta$ associated with the continental slope plays a role in ripping apart a shoreward propagating mesoscale-dipole that crashes into the slope. Likewise, the planetary $\beta$ contributes a northwestward propagation tendency to the anticyclone and a southwestward tendency to the cyclone, which can break up the newly formed and intense mesoscale dipole as it began to propagate towards the northwest.

Dispersion can locally fuel the thermocline via leakage of eddy water. The ventilation process associated with these mixed eddy structures is beyond the scope of this work. However, as Agulhas eddy A19 interacted with the shelf, it began to break apart, into smaller anticyclonic eddies, and part of the A19 eddy continued to interact with the shelf and form a cyclonic partner (Fig. 7). Two of these smaller anticyclones move away with a cyclone, two new dipole structures that carry water seaward. The resulting dipole kinematics can export water properties away from the formation region. 
In the presence of stratification, topography, and other ocean currents, a counter-rotating eddy structure can mix and advect water properties. The amount of mixing compared to the amount of advection in a dipole structure remains to be quantified. Results presented in this study were consistent with observations of strong vorticity driven advection and suggest that during the advection process local mixing is relatively weak and during the formation process leakage takes place in the form of filaments. Most of the local mixing is thought to occur during the formation and collapse of such dynamic structures, while most of the advection takes place when the counter-rotating vortices are of comparable strength such that they propel one another. These structures provide a key aspect of ocean variability that can be understood in the context of quasi-geostrophic barotropic flow. Their dynamics with regard to water mass distribution may play a role in mode water formation and/or deep lens formation.

Although we have not examined the ventilation process associated with counter-rotating eddy structures, the collision of a heton-like dipole with the continental slope appears to provide an environment for enhanced vertical exchange. Further studies are required to trace the water properties in such large eddy-slope generated cyclonic eddies. Swaters and Flierl (1991) analyzed the internal structure and interaction characteristics of cold-core eddies on a sloping bottom and found a correlation between decay of the translation speed and the process of ventilation, which stimulated topographic Rossby waves. Cyclonic eddies can aid in the advection of Agulhas eddies out of the Cape Basin (Baker-Yeboah, 2008) and are important in the evolution of Agulhas rings, as these eddies translate and mix into the the basin scale ocean circulation. In addition to advection, some cyclonic eddies may play a role in the ventilation process of Agulhas eddies, as well as shelf and slope water - although weak compared to advection. Furthermore, the Cape Basin may export volumes of water via cyclonic eddies along the continental slope into the Agulhas Retroflection regime. Such transport may or may not occur at the same time as the shedding of an Agulhas ring, which imports material to the Cape Basin region. The eddy exchange process is not thought to be limited to inflow in the upper layer and export in the lower layer, such as in most box model constructs of import and export. Mixed baroclinic-barotropic eddies couple the water column (Baker-Yeboah, 2008), and further studies are needed to understand the circulation and transport of these cyclonic eddies. We suspect that thermocline, intermediate, and deep water get transported out of the Cape Basin and into the Agulhas Basin where they can coalesce with the Agulhas Retroflection regime in the form of cyclonic eddies. Taking into account the development of cyclonic eddies on the western side of southern Africa along with an Agulhas anticyclone allows one to conclude that dipoles can also form along the eastern boundary slope region of the South Atlantic.

\section{Conclusions}

In conclusion 1) a mixed barotropic-baroclinic cyclone with both slope and shelf water can form due to the interaction of a deep reaching Agulhas eddy with slope and together form a heton-like dipole, 2) heton-like dipoles can move water onto or off the shelf/slope region, and 3) these self-propagating structures provide a conduit for mixing via filament-entrainment between the deep ocean and shelf regions in the Benguela upwelling system. Further, 4) this process can increase the number of cyclones in the Cape Basin. Lastly, 5) the image effect and eddy-continental slope interactions produce nonlinear advection of potential vorticity $(\mathrm{PV})$ and are controlling dynamical mechanisms that lead to the formation of the counter-rotating partner and dipole motion from the slope region.

Acknowledgements. We acknowledge and thank the National Science Foundation for grant \# OCE-0752346, the principal support for this work. Many thanks to Deirdre A. Byrne and D. Randolph Watts for use of the Agulhas South-Atlantic Thermohaline Transport Experiment (ASTTEX) data.

Edited by: J. A. Johnson

\section{References}

An, B. W. and McDonald, N. R.: Coastal currents and eddies and their interaction with topography, Dyn. Atmos. Oceans, 40, 237253, 2005.

Arhan, M., Mercier, H., and Lutjeharms, J. R. E.: The disparate evolution of three Agulhas rings in the South Atlantic Ocean, J. Geophys. Res., 104, 20987-21005, 1999.

Baker-Yeboah, S.: Sea Surface Height Variability and the Structure of Eddies in the South Atlantic Cape Basin, Ph.D. Dissertation, University of Rhode Island, Narragansett, 308 pp., 2008.

Baker-Yeboah, S., Byrne, D. A., and Watts, D. R.: Observations of Mesoscale Eddies in the South Atlantic Cape Basin: Baroclinic and Deep Barotropic Eddy Variability, in preparation, 2010.

Baker-Yeboah, S., Watts, D. R., and Byrne, D. A.: Baroclinic and Barotropic Sea Surface Height Variability in the Southeast Atlantic from Pressure-Sensor Equipped Inverted Echo Sounders, J. Atmos. Ocean. Tech., 26, 2593-2609, 2009.

Bang, N. D.: Characteristics of an intense ocean frontal system in the upwell regime west of Cape Town, Tellus, 25, 256-265, 1973.

Bang, N. D. and Andrews, W. R. H.: Direct current measurements of a shelfedge frontal jet in the Southern Benguela System, J. Mar. Res., 32, 405-417, 1974.

Boebel, O., Lutjeharms, J., Schmid, C., Zenk, W., Rossby, T., and Barron, C.: The Cape Cauldron: a regime of turbulent interocean exchange, Deep-Sea Res. II, 50, 57-86, 2003.

de Steur, L., van Leeuwen, P. J., and Drijfhout, S. S.: Tracer Leakage from Modeled Agulhas Rings, J. Phys. Oceanogr., 34, 13871399, 2004.

Duncombe Rae, C. M.: Agulhas Retroflection Rings In the South Atlantic Ocean: An Overview, S. Afr. J. Mar. Sci., 11, 327-344, 1991. 
Duncombe Rae, C. M., Garzoli, S. L., and Gordon, A.: The eddy field of the south-east Atlantic Ocean: a statistical census from the BEST Project, J. Geophys. Res., 101, 11949-11964, 1996.

Flierl, G. R.: Thin jet and contour dynanics models of Gulf Stream meandering, Dyn. Atmos. Oceans., 29, 189-215, 1999.

Frolov, S. A., Sutyrin, G. G., Rowe, G. D., and Rothstein, L. M.: Loop Current Eddy Interaction with the Western Boundary in the Gulf of Mexico, J. Phys. Oceanogr., 34, 2223-2237, 2004.

Gordon, A. L.: Indian-Atlantic Transfer of Thermocline Water at Agulhas Retroflection, Science, 227(4690), 1030-1033, 1985.

Hogg, N. and Stommel, H.: The heton, an elementary interaction between discrete baroclinic geosrophic vortices, and its implications concerning eddy heatflow, Proc. Roy. Soc. London Ser. B, 397A, 1-20, 1985.

Lutjeharms, J. R. E. and Ballegooyen, R. V.: The Retroflection of the Agulhas Current, J. Phys. Oceanogr., 18, 1570-1583, 1988.

Lutjeharms, J. R. E. and Valentine, H. R.: Eddies at the Subtropical Convergence South of Africa, J. Phys. Oceanogr., 18, 761-774, 1988.

Lutjeharms, J. R. E., Shillington, F. A., and Duncombe Rae, C. M.: Observations of Extreme Upwelling Filaments in the Southeast Atlantic Ocean, Science, 253, 774-776, 1991.

Lutjeharms, J. R. E., Boebel, O., and Rossby, H.: Agulhas cyclones, Deep-Sea Res. II, 50, 13-34, 2003.

Matano, R. P. and Beier, E. J.: A kinematic analysis of the IndianAtlantic interocean exchange, Deep-Sea Res.II, 50, 229249, 2003.

Meacham, S. P.: Meander Evolution and Piecewise-Uniform, Quasi-geostrophic Jets, J. Phys. Oceanogr., 21, 1139-1170, 1991.

Polvani, L. M.: Geostrophic vortex dynamics, Massachusetts Institute of Technology, Massachusetts, MA, 221 pp., Dissertation, 1988.

Polvani, L. M.: Two-layer geostrophic vortex dynamics. Part 2. Alignment and two-layer V-states, J. Fluid Mech., 225, 241-270, 1991.

Richardson, P. L., Lutjeharms, J. R. E., and Boebel, O.: Introduction to the "Inter-ocean exchange around southern Africa", Deep-Sea Res. II, 50, 1-12, 2003.

Sanson, L. Z. and van Heijst, G. J. F.: Interaction of Barotropic Vortices with Coastal Topography, J. Phys. Oceanogr., 30, 21412162, 2000.
Shi, C. and Nof, D.: The splitting of eddies along boundaries, J. Mar. Res., 51, 771-795, 1993.

Shi, C. and Nof, D.: The Distruction of Lenses and Generation of Wodons, J. Phys. Oceanogr., 24, 1120-1136, 1994.

Smith, D. C. I.: A Numerical Study of Loop Current Eddy Interaction with Topography in the Western Gulf of Mexico, J. Phys. Oceanogr., 16, 1260-1272, 1986.

Smith, D. C. I. and O'Brien, J. J.: The Interaction of a Two-Layer Isolated Mesoscale Eddy With Bottom Topography, J. Phys. Oceanogr., 13, 1681-1697, 1983.

Sutyrin, G. G. and Flierl, G. R.: Intense Vortex Motion on the Beta Plane: Development of the Beta Gyres, J. Atmos. Sci., 51, 773790, 1994.

Sutyrin, G. G., Rowe, G. D., Rothstein, L. M., and Ginis, I.: Baroclinic Eddy Interactions with Continental Slopes and Shelves, J. Phys. Oceanogr., 33, 283-291, 2003.

Swaters, G. E. and Flierl, G. R.: Dynamics of ventilated coherent cold eddies on a sloping bottom, J. Fluid Mech., 223, 565-587, 1991.

Tenreiro, M., Sanson, L. Z., and van Heijst, G. J. F.: Interaction of dipolar vortices with a step-like topography, Phys. Fluids, 18, 056603, doi:10.1063/1.2204070, 2006.

Thompson, L.: Two-Layer Quasigeostrophic Flow over Finite Isolated Topography, J. Phys. Oceanogr., 23, 1297-1314, 1993.

van Aken, H. M., van Veldhoven, A. K., Veth, C., de Ruijter, W., van Leeuwen, P., Drijfhout, S., Whittle, C. P., and Rouault, M.: Observations of a young Agulhas ring, Astrid, during MARE in March 2000, Deep-Sea Res. II, 50, 167-197, 2003.

Wang, X.: Interaction of an eddy with a continental slope, Ph.D. Dissertation, Massachusetts Institute of Technology, Woods Hole Oceanographic Institution, 216 pp., 1992.

Whittle, C., Lutjeharms, J. R. E., Duncombe Rae, C. M., and Shillington, F. A.: Interaction of Agulhas filaments with mesoscale turbulence: a case study, S. Afr. J. Sci., 104, 135-139, 2008.

Wu, H. M., Overmane, A., and Zabusky, N. J.: Steady state solutions of the Euler equation in two dimensions. Rotating and translating V-states with limiting cases. I. Numerical results., J. Comput. Phys., 53, 42-71, 1984.

Zabusky, N. J., Hughes, M. H., and Roberts, K. V.: Contour dynamics for the Euler equations in two dimensions, J. Comput. Phys., 30, 96-106, 1979. 